\title{
Theorizing Teacher Responsibility in an Age of Neoliberal Accountability
}

\author{
Tina Besley \\ Distinguished Professor, Beijing Normal University, PR China \\ tbesley@bnu.edu.cn
}

\begin{abstract}
This article explores concepts of teacher responsibility, accountability, being in loco parentis, and responsibilization as many advanced capitalist societies have dropped policies and practices that were set up in the mid 19th century after the Great Depression in the welfare state under Keynesian economics. Since the early 1980s most of these states have adopted neoliberal policies and market rationality for all aspects of social policy including education. Under neoliberalism, the subject theorised by Homo economicus, is one that is theorised as a rational autonomous individual, with its responsibilized behavior underpinning much of how not only teachers but students now are compleed to behace and perform. These have resulted in major shifts in attitudes to professionalism of teachers, in responsibilising individuals and so have impacted on subjectivity as the state has pulled back from all manner of social provision and has responsibilized the individual to be a consumer-citizen, a prudential and entrepreneurial self even in terms of education. The upshot is increasing use of audits, checklists and accountability regimes for teachers who are becoming increasingly a de-professionalised in a low-trust managerialist environment with students as consumers.
\end{abstract}

\section{Keywords}

responsibility - neoliberalism - accountability - homo economicus - loco parentis professionalism - moral constitution 
Responsibility is a key concept in our lives with moral, social, cultural, financial and political aspects. It embraces two main forms - legal and moral - and takes different forms in relation to personal, professional, corporate and social dimensions. The etymology of "responsibility" suggests that it surfaces around the 1590 s in French and Latin with the meaning of being answerable to someone or for something (from the Latin respons), and later in the 1640 s for being accountable for one's actions: two senses often conflated in modern discussions. The state of being accountable or answerable for one's actions and can also imply a sense of obligation or duty normally associated with being in a position of authority such as a parent, teacher or guardian with authority over children or minors.

In terms of responsibility, professionals such as teachers are often considered to be involved in a process called "responsibilization' which means "making responsible." Often, but not exclusively, responsibilization is associated with Foucault's analysis of neoliberal governmentality. Foucault provides a nuanced reading that comes from naturalising and historicising Kant and thereby also emphasising some continuity between liberalism with an emphasis on individual autonomy and neoliberalism that also emphasises individuality and rationality from within a perspective that focuses on self-interest where greater good is a result of the "invisible hand." Sometimes the term has been also used by those embracing Ulrich Beck's concept of the "risk society" and an analysis of the neoliberal state that has been privatising and individualising social provision through the use of a market rationality. Many Western democracies now follow neoliberal principles that use market-like arrangements such as contracting-out, public-private partnerships, user-pays, and other parallel mechanisms for the privatisation of the social welfare state. There has been a shift from state responsibility under former Keynesian-oriented welfare state systems to a neoliberal policy environment that uses responsibilization not only of teachers, but also of students as consumers, and associated forms of discourse, accountability and assessment regimes. This market rationality is employed to responsibilize the individual and to naturalize regimes of selfcare. At this point it is important to caution against conflating responsibility with responsibilization, since these are different concepts that originate in different "moral" traditions. While responsibilization is more of a neoliberal technology of the self that forces an individualism on society and exports

1 Parts of this article are adapted from Besley, Tina (A.C) \& Peters, Michael A. (2019) Teaching, Responsibility, and the Corruption of Youth. Leiden | Boston: Brill/Sense. 
responsibility from state to individual, it has not been taken up by all actors in education, particularly young people and teachers. The concept of responsibility remains central to interpersonal relations and the matter of who is responsible cannot be excised from history or social context.

\section{In Loco Parentis}

To begin the discussion theorising responsibility of teachers, I examine the Latin phrase, in loco parentis, that simply means "in place of the parent" and was originally derived from English Common Law precedent of 1770 . Traditionally children were not regarded as bearers of rights because they were not considered adults and parents were held to act in their self-interest while teachers acted in loco parentis. The concept was first adopted as a motto by the Manchester Warehousemen and Clerks' Orphan Schools in 1855 and was applied to wards of the state. Subsequently as universal schooling developed it became widely used in education where it gives teachers, educational institutions and guardians legal responsibilities for specific functions to act as a parent would in the best interests of the child/ student without infringing on their civil rights. Notions of pastoral care are often used in this context as is discipline of students.

When minor children are entrusted by parents to a school, the parents delegate to the school certain responsibilities for their children, and the school has certain liabilities. In effect, the school and the teachers take some of the responsibility and some of the authority of the parents. The exact extent and nature of this responsibility and power vary from one society to another and from one school system to another. This is spelled out to some extent in the law, but much of it is determined by local custom and practice. (https://www.britannica.com/topic/teaching/ The-doctrine-of-in-loco-parentis)

Teachers administering discipline are seen not merely as acting as parents but as representatives of the state. Being in loco parentis permitted and justified the legal administration of corporal punishment in schools in much of the world until the 1980s. Familiar sayings such as "Spare the rod, spoil the child" exist in many places. From having once been able to administer corporal punishment, by 2016 approximately128 countries (all of Europe, most of South American and East Asia) totally ban physical punishment of students. Yet it is still permitted in some 69 countries in parts of Africa, South East Asia, the 
Middle East, in Singapore, Malaysia, some Australian and u.s. states (Gershoff, 2017). The Global Initiative to End All Corporal Punishment of Children, notes that corporal punishment was officially banned in China after 1949 and that the Compulsory Education Law of 1986 states: "It shall be forbidden to inflict physical punishment on students" (https://endcorporalpunishment.org/) yet apparently in rural areas teachers still seem to beat children. ${ }^{2}$ As part of this change in disciplining children and young people, some countries now ban parents or any adult from physically punishing children.

In the pastoral care aspect of loco parentis being applied, contemporary issues and controversies sometimes arise in particular with personal counselling and social workers in schools, and parental rights. Questions arise: What remains confidential, what needs to be disclosed, to whom? Under what circumstances? Of major concern here are sexual behaviours, referrals to outside health authorities (e.g., for contraception, STD or abortion services) and also suicidal ideation. In general school counsellors are bound by client confidentiality through the codes of ethics of professional bodies to which they belong, nevertheless they also are often responsible for informing parents in the event of potential serious harm to self or others by students. Pastoral care is now open to greater scrutiny as many of the main agencies for the care of children, students and teenagers, both public and private, have been exposed as being based on a range of unacceptable punishments including solitary confinement, violence, and physical, sexual and emotional abuse. ${ }^{3}$

2 See: https://endcorporalpunishment.org/reports-on-every-state-and-territory/china/. "Corporal punishment is prohibited in schools. Article 16 of the Compulsory Education Law 1986 states: "It shall be forbidden to inflict physical punishment on students." According to article 37 of the Teachers' Law 1994, teachers "imposing corporal punishment on students and refusing to mend their way after being criticised" are subject to administrative sanctions or dismissal and "if the circumstances are serious enough to constitute a crime, shall be investigated for criminal responsibility according to law". The Law on the Prevention of Juvenile Delinquency 1999 prohibits corporal punishment in work-study schools for children found to have perpetrated serious misbehaviour (art. 36): “... Families and schools shall show concern for and take good care of the juveniles who study in work-study schools and respect their personality and dignity, and may not impose physical punishment on, maltreat, or discriminate against them...." The prohibition is confirmed in article 21 of the Law on the Protection of Minors 2006 (see under "Day care")."

3 See, for instance, the Australian Royal Commission into the Institutional Responses to Child Sexual Abuse, https://www.hildabuseroyalcommission.gov.au/. See also "The prevalence of child abuse and neglect" (2017), https://aifs.gov.au/cfca/ publications/ prevalence-child-abuse-and-neglect. 
Prior to the 196os even students in higher education who were still minors, experienced many restrictions on their private lives including curfews and dress codes especially for women. The Student Free Speech Movement at Berkeley challenged many of these restrictions in the mid-196os based on the students' rights to free speech and academic freedom especially in relation to campus political activities. In USA, 1st amendment rights of students in public schools are not generally seen as co-extensive with those of adults in other settings. Private institutions by contrast are generally given more authority over their student charges. The concept is still being refined: dress codes and lockers, cell phones or computer searches have not yet been tested in court. Student freedom of expression is considered by some judicial authorities to be significantly limited by in loco parentis. Generally, since the late 2oth century in loco parentis has become more of an anachronism since it has limited legal relevance in many places once specific legislation for student health and wellbeing has been established. Nevertheless it stresses an important ethic or duty of care that all teachers and educators should hold for their students.

\section{Responsibility}

In this brief initial analysis already we can see that the concept of responsibility implies a notion of (see Eshleman, 2009 on "moral responsibility") agency and accountability for one's actions, often attached to a particular role. In terms of our moral vocabulary it is a concept that it relatively recent and one that springs from two quite different traditions. Garreth Williams (n.d.) maintains that the word only finds a home in the political debates on representative government in the eighteenth century and only later in twentieth century philosophy does it establish its own language game when the concept is introduced based on debates concerning free will, causation and determinism. This etymology suggests that the concept came into being at the same time that notions of autonomy, the individual and the subject began to form within the liberal network of rights and the citizen.

"Professional personality" emerged much later again with the development of professional ethics that while its origins date from the adoption of the Hippocratic oath by medical practitioners in the fifth century really only came in widespread use and adoption in the twentieth century. Increasingly when professionals utilize specialist knowledge and skills in the service of the public they are required to adhere to the norms of confidentiality, transparency, integrity, and honesty as formulated and regulated by a professional code of practice. It probably began in earnest with moral rules of professional conduct 
governing the conduct of lawyers in the court although the word professional has roots to "profess" and is associated with the concept of confession made by a person entering a religious order and is therefore connected to the idea of a calling. Teaching is considered a "calling" that implies a commitment of care. This includes responsibilities, duties and obligations often to minors and to children on whose behalf teachers, as professionals, must act, but also to those adults who are deemed incapable or unable to act in their own self interests. Professionals in this sense are seen as occupying a place between the state and the public based on a relationship of trust and good faith. They are presumed to act in the service of the public for the common good on behalf of the community to undertake specific functions based on their knowledge and skills.

Official accounts of teacher professionalization often focus on and responsibility tend to emphasise the behaviours that teachers ought to exhibit or model - "The teacher as a person" - with an accent on vocational qualities like empathy, trust, confidence, high student expectations, equal treatment, good communication skills, "a professional manner", "a sense of humour". This constitutes a "personalogical" approach to teacher responsibility and often involves the mere statement of these qualities as though they were self-evident and require no theoretical interpretation of justification.

In other approaches teachers are seen as being responsible for "classroom management and organization" with an accent on the "well-ordered" classroom that is nevertheless arranged or "grouped" in order to promote interaction and discussion with fair access to instruction and classroom teaching materials. Teachers are responsible for determining content of lessons under curriculum guidelines to promote high-quality instruction that progressively develops a syllabus and observes the national curriculum guidelines. This is surely an aspect of teacher professionalism that is based on subject knowledge on the one hand and teaching experience and understanding on the other. It is a form of professional preparation and preparedness that leads on naturally to teaching itself and to the act of instruction including all the criteria concerning logical structuring of material that encourages higher thinking skills, student questioning, assessment and different forms of learning. Sometimes teacher education programs lay down subject specific responsibilities such as that of the English teacher who should provide good listening behaviours, or offer opportunities for different kinds of speech acts, class discussion or experience of written genres. A science teacher might be reminded about special lab safety conditions, or the means of progressing in science through "discoveries" 
and "investigations" that highlights the collection and analysis of facts. Assessment in particular has become a large part of the professional responsibility of teachers including all aspects of monitoring and managing student progress and its effective recording often in relation to national standards. These can be regarded as "compliance" forms of responsibility where the teacher is required to abide by standards laid down by statutory authority.

In addition to these tasks focused on the act of teaching, authorities often specify certain administrative, community, and parental responsibilities as well as the capacity to respond to certain groups of students labelled as "atrisk", special needs or "high-ability" students, to those with disabilities, or with special health needs, or with drug problems. Many accounts of teacher responsibilities highlight the relationship and treatment of learners such as the need to " $\mathrm{t}]$ reat learners fairly, respectfully, and without bias related to their age, race, gender, sexual orientation, disability, religion, or national origin". ${ }^{4}$ Many authorities also discuss "Responsibility in Professional Relationships" and "Responsibility in Relationships with Patients and Families". In addition they differentiate within the teaching profession emphasising different responsibilities of the "classroom teacher", "curriculum team leader", "head of department" or "head teacher" or principal.

Fani Lauermann (2013, p. 1) in her thesis "Teacher Responsibility: Its Meaning, Measure, and Educational Implications" writes:

Teachers' personal sense of responsibility potentially influences their instructional practices, psychological well-being, and ultimately their students' learning and performance. Various conceptualizations of teacher responsibility have been linked to such outcomes as positive attitudes toward teaching and professional dedication (Halvorsen, Lee, \& Andrade, 2009), job satisfaction (Winter, Brenner, \& Petrosko, 2006), positive affect toward teaching (Guskey, 1984), teachers' beliefs in their ability to influence students, teachers' willingness to implement new instructional practices (Guskey, 1988), and with student achievement (Lee \& Smith, 1996, 1997). Furthermore, the assumption that teachers are personally responsible, or that they should assume personal responsibility for their students' educational outcomes - primarily test performance - is at the core of high-impact educational policies such as the implementation of accountability systems in American schools (Linn, 2006, 2010; Schraw, 2010).

4 See https://hms.harvard.edu/departments/office-registrar/student-handbook/4-student -conduct-and-responsibility/401-responsibilities-teachers-and-learners. 
Her analysis of the extant literature on teacher responsibility demonstrates conceptual and operational ambiguity: "the term responsibility has been used interchangeably with related constructs such as internal locus of control and teacher efficacy, measurement instruments have incorporated items originally designed to assess other constructs such as efficacy, and have generally failed to acknowledge the multidimensional nature of teacher responsibility, and the literature lacks a comprehensive and consistent definition of the term" (Lauerman, 2013, p. 1). She adopts Lenk's (1992) six-component framework of teacher responsibility: (a) Who is responsible? (b) For what? (c) For/to whom? (d) Who is the judge? (e) In relation to what criteria? and (f) In what realm? Her analysis of different conceptualizations of responsibility suggests that it reflects "a sense of internal obligation and commitment to produce or prevent designated outcomes or that these outcomes should have been produced or prevented" (p. 42). But this is a literature based analysis and synthesis from an educational psychological view rather than a philosophical, political or historical analysis of a changing concept.

4

\section{Accountability Regimes in Audit Cultures: The Shift from Liberalism to Neoliberalism}

Responsibility is increasingly defined as a duty or obligation to fulfil or complete a task related to a profession, to universally accepted moral obligation or to a majority or group of people as a form of political accountability. Accountability and the rise of audit cultures have accompanied neoliberalism and new managerialism in the public sector, including education. As Michael Power (1994, p. 47) argues: "Audit is an emerging principle of social organization [that] ... constitutes a major shift of power: from the public to the professional, and from teachers, engineers and managers to overseers". Such conceptual and operational ambiguity results from a profound change in the concept of responsibility that reflects the shift from liberalism which is based in individual and professional autonomy and moral agency, to neoliberalism which is based on a thin concept of market accountability. Increasingly this shift has resulted in the collapse of moral and legal responsibility and the promotion of a form of accountability oriented regulation that so often results in de-professionalising teachers who become form-filling, compliant docile bodies regularly proving that are acting in compliance with accountability requirements, seldom questioning the use and purpose of such data that is gathered. 
There are, roughly speaking four different contemporary forms that comprise "accountability" or accountability regimes. They are not mutually exclusive and may exist as hybrids. First, is state-mandated agency form of accountability that regulates activity or performance according to standards or criteria laid down at state or federal level? Typically, this form is associated with devolution of management (though not necessarily governance) and the development of parallel privatisation and/or the quasi market in the delivery of public services. Second, there is professional accountability which tends to operate through the control of entry and codes of practice established by professional associations, most often in occupations like law, accountancy, dentistry, medicine, nursing, counselling. Teaching is subject to professional self-regulation in some countries but not others. Third, is consumer accountability, that is, accountability through the market, especially where consumer organisations have been strengthened in relation to the development of public services delivered by markets or market-like arrangements? Fourth, is a form of democratic accountability that is premised on the demand for both internal and external accountability, typically accountability of a politician to parliament or governing organisation and accountability to an electorate? The second form or professional accountability may be seen, in reality, to be a form of the fourth or democratic form. Both proceed from Kantian-like assumptions about autonomy, self-regulation, duty and responsibility for one's actions whether this be considered in institutional (e.g., parliament, university) or individual terms. There has been a tendency in Western liberal states to emphasize both agency and consumer forms at the expense of professional and democratic forms, especially where countries are involved in large-scale shifts from traditional Keynesian welfare state regimes to more market-oriented and consumer-driven systems. Indeed, it could be argued that there are natural affinities by way of shared concepts, understandings and operational procedures between these two couplets. One of the main criticisms is that the agency/consumer couplet instrumentalises, individualises, standardises, marketises and externalises accountability relationships at the expense of democratic values such as participation, self-regulation, collegiality, and collective deliberation that are said to enhance and thicken the relationships involved.

\section{Responsibilization and Homo Economicus}

"Responsibilization" refers to modern forms of self-government that require individuals to make choices about lifestyles, their bodies, their education, 
and their health at critical points in the life cycle, such as giving birth, starting school, going to university, taking a first job, getting married, and retiring. "Choice" assumes a much wider role under neoliberalism than under the welfare oriented state: it is not simply "consumer sovereignty" but rather a moralization and responsibilization, a regulated transfer of choice-making responsibility from the state to the individual in the social market. For education "school choice" is the central notion for the privatization agenda. In USA its forms include voucher systems that use public money to pay for private and religious school tuition or provide tax credits to people who contributed money for such purposes; also setting up charter schools that are publicly funded but privately operated, frequently by for-profit companies.

Pat O'Malley, an Australian Foucauldian theorist, notes that the concept of "responsibilization" developed in the 1990 in the governmentality ${ }^{5}$ (Foucault's neologism, government rationality, meaning "conduct of conduct") literature

... to refer to the process whereby subjects are rendered individually responsible for a task which previously would have been the duty of another - usually a state agency - or would not have been recognized as a responsibility at all. The process is strongly associated with neoliberal political discourses, where it takes on the implication that the subject being responsibilized has avoided this duty or the responsibility has been taken away from them in the welfare-state era and managed by an expert or government agency (2009, p. 276).

O'Malley explains how the term responsibilization describes the neoliberal assumption that the old welfare state had robbed citizens of their independence and made them dependent on the state. Neoliberal strategies reverse this process, making subjects responsible for themselves, taking responsibility for governing themselves and their lives. This "reversal" of responsibility is often stated as "no rights without obligations", but is in effect "victim blaming" since the State devolves its responsibilities. O'Malley points out that responsibilization has supporters from across the political spectrum who criticize the state and look for greater citizen involvement, control and responsibility. Such arguments resonate with the 1960 s and 70 s critiques of state power as exercised through large centralized institutions, that saw deinstitutionalization, community devolution and control promoted by the likes of Ivan Illich (deschooling), and Michel Foucault and David Cooper in mental health, medical fields.

5 For more on governmentality, see Peters, M.A., Besley, A.C., Olssen, M., Maurer, S., \& Weber, S. (Eds.)(2009) Governmentality Studies in Education. Rotterdam: Sense Publishers. 
However, under neoliberalism, State power and authority is reformulated in terms of market rationality, where the citizen subject is expected (or even forced through new regulations) to adopt responsibilization strategies that promise they will gain freedom by making consumer choices in the marketplace for all aspects of their lives including social welfare and education provision. The State forces such responsibility and responsibilization onto the individual, families and professionals (who are responsible and may be contracted to provide services), as it steps back from active social provision. It devises policy, practices and juridical frameworks that establish the rules governing social distribution, and set criteria for their continual monitoring, performativity and auditing, that mean there really is in fact very limited choice after all - rather, the illusion of choice.

In this new market environment we find a shift in subjectivity and a new individualism arising that strips away all collective value and responsibilities the individual to take care of themselves through enhanced choice-making in the market place to the exclusion of all other ethical values and social interests. The subject, according to neoliberalism, is theorized as a rational autonomous individual in all its behavior, as Homo economicus ("economic man") that is expected to look after him/herself, modeled on three assumptions of individuality, rationality and self-interest. The rejuvenation of Homo economicus, makes individuals as citizen-consumers calculate the risks and invest in themselves at critical points in the life cycle. As Foucault writes, "Homo economicus is an entrepreneur, an entrepreneur of himself" (Foucault, 2008, p. 226). The construction of Homo economicus leads to a double strategy of the economization of state and civil society institutions and the moralization of the market where the primary shift in responsibility is away from the State - a State-shedding of responsibility while retaining the power to strike norms of assessment and control - toward the private sector in all areas of social provision including pensions, welfare, health and education. Responsibilization thus functions as a technique for the self-management and self-regulation of social risks such as illness, unemployment and poverty (Lemke, 2001).

This neoliberal subject is thus an individual who is transparent to itself and morally responsible for navigating the social realm using rational choice and cost- benefit calculations - a new kind of prudentialism or actuarial rationality - grounded on market-based principles. The "responsibilized" self who must make choices regarding his or her own welfare then becomes the prudential self, the actuarial self, and the entrepreneurial self (see Peters, 2006; Besley \& Peters, 2007). Such prudentialization seeks to "insure" the individual against risk in a context where the state has transferred risk to the individual. 
A genealogy of the entrepreneurial self reveals that it is a relation that one establishes with oneself through forms of personal investment in the self in an individualized, customized, and privatized consumer welfare economy. Here responsibilized individuals need to apply certain managerial, economic, and actuarial techniques to themselves as citizen-consumer subjects calculating the risks and returns on investment in such areas as education, health, employment, and retirement. More so than ever, with high course fees and burgeoning student loans, education is viewed as an investment in the self. This process is both self-constituting and self-consuming. It is self-constituting in the Foucauldian sense that the choices we make shape us as moral, economic, and political agents. It is self-consuming in the sense that the entrepreneurial self creates and constructs him- or herself through acts of consumption. In education we find that course evaluation has become in effect a form of populism that accepts student opinions about courses, their usefulness rather than any attempt to the measure quality of ideas. In higher education the upshot now so often is that unpopular courses or those deemed not "useful" or practical, or profitable or having direct economic benefit or "value" for getting a job or profitable for the university are being deleted, such that the humanities and social sciences are currently under serious threat especially in the West.

In this neoliberal environment, at first there is often an emphasis on deregulation and the empowerment of consumers. But increasingly there has been a shift with a belief in the efficacy of rules and a distrust of expert and professional knowledges resulting in a re-regulation and an intensive juridification where the government assumes the metaposition of rule-maker. A framework of rules and codification allows the government to step back more and more from actual involvement in state activities, which now devolve to agencies, institutions, or regions. In this political environment, the economic, constitutional, and legal or juridical forms of advanced liberalism overlap to construct the citizen-consumer, simultaneously their individualization and their responsibilization.

Professionalism - Power and Responsibility

Traditional conceptions of professionalism involved an ascription of rights and powers and responsibilities for work in line with classical liberal notions of freedom of the individual. Professionalism conveys the idea of a subjectdirected power, based upon the liberal conceptions of rights, freedom and autonomy. It conveys the idea of a power given to the subject, and of the subject's ability to make decisions in the workplace. No professional, whether doctor, 
lawyer or teacher, has traditionally wanted to have the terms of their practice and conduct dictated by anyone else but their peers, or determined by groups or structural levers that are outside of their control.

As a particular patterning of power, professionalism is systematically at odds with neoliberalism, for neoliberals see the professions as self-interested groups who fiercely protect their expert knowledge and practices and indulge in "rent-seeking" behavior. In neoliberalism the patterning of power is established through contract, which in turn is premised upon a need for compliance, monitoring, and accountability, and organized or managed via a line management system, a workload model and established through employment contracts based upon measurable key performance indicators (KPI's) and outputs.

Market pressures increasingly encroach and redesign these traditional understandings of professional rights and responsibilities, as educational institutions must adapt to market trends. For example, individual departments and academics are being told the must acquire external research grants; they are also having to teach more courses based on the EFTs (Equivalent full-time students) model that penalizes small classes and the use of standardized workload models. There is a whole literature now emerging about the precarity of all positions in education from schools to universities. Neoliberal line management systems or managerialism inserts a hierarchical mode of authority by which the market and state pressures can be instituted. For teachers and universities this often results in de-professionalization as it involves a shift from collegial forms or democratic flat governance structures, to hierarchical models based on dictated management specifications of job performance in chains of command. The implementation of regular restructuring in response to market and state demands (e.g. student numbers for courses) involves increasing specifications by management over workloads and course content by management. Such hierarchically imposed specifications erode traditional conceptions of professional autonomy over work in relation to both teaching and research. Neoliberalism systematically deconstructs and destroys the space in terms of which professional autonomy is exercised. In effect these systems are a direct attack on professionalism that de-professionalizes teachers and professors and are a move towards centralized standardization and control.

State responsibilization for welfare (the welfare state) was achieved politically using Keynesian economic theories and through the power of trade unions and working people in post-Great depression and the post WW II context. It 
did not devolve all power to the State to encourage an overweening sense of dependency, but at its best emphasized a citizen active participation within State provided social and public infrastructures that led to the co-creation and co-production of social goods. The negative story of dependency is part of a neoliberal narrative that emphasizes the way that the welfare state robbed economic liberalism of it vitality. By substituting the market and employing the moral vocabulary of individual choice-making neoliberals have reinvented subjectivity and the market in moral terms that allows a shrinking state and a kind of parallel privatization that increasingly sees private sector companies taking over the responsibility for running what used to be public institutions. The logic of public-private partnerships further drives this strategy more deeply into the social fabric. Yet the basic forms of citizen participation and active co-production at the heart of social democracy remains a clear and viable option for the provision of welfare and social security.

Responsibilization is one of the major strategies and practices of a neoliberal moralization of markets that shifts responsibility from the State to the citizen. Forms of "responsibilization" are taking place in education that create different forms of subjectivity that are morally self-constituting through the mechanism of freedom and choice within current neoliberal environments. Today there has been narrowing to focus largely on consumer rights as the user-pays policies and forms of privatization in education have been established by neoliberals. In a consumer-driven system the emphasis has changed to consumer sovereignty and consumer rights with increasing shifts to issues of security and privacy. The question of access and equality has dropped off the political agenda and now across the Western world the issue of student poverty has become a huge problem along with student indebtedness. Securitization has led to the expression of freedom of expression and freedom of movement. The history of student rights is a relatively recent phenomenon. ${ }^{6}$

Since Ancient Greek times, citizens, political leaders and philosophers have argued about the wellbeing of youth, their education, their morality and how best to mould youth as responsible citizens. At the same time, education has been identified with a range of different ways of enhancing or inflaming youth passions - as a means to incite or prevent revolution, violence and terrorism. Education may be considered a form of indoctrination or political socialization especially when particular regimes set out to politicize notions of culture, religion and national identity. Moreover, teachers and their ideas can have considerable impact on student attitudes and actions as exemplified by the

6 http://psych.fullerton.edu/mbirnbaum/psych466/LG/academicinterestspage.htm. Teachers, Responsibility and the Resistance of Youth xxi. 
famous charges of corrupting youth and impiety against Socrates in Ancient Greece. Charges of the corruption of youth and incitement to rebellion have been levelled at teachers in the context of Nazism, the Cold War, the Vietnam era, Christian fundamentalism and Jihadism.

In the contemporary neoliberal world, the question of teacher responsibility has been narrowed as a professional concept closely related to a duty of care. Yet it is in an increasingly legally complex environment for teachers to navigate with the growing involvement of parents, parental organizations, teacher associations, state agencies, and new private and public sector organizations like business roundtables that make pronouncement on the role and responsibilities of teachers. Arguably, teachers ought to teach students "response-ability" based on an ethics of caring for others - the response-ability towards others, rather than focus on the "account-ability" demanded by neoliberals. The latter is a thin narrow accounting notion associated with a passive project of the subject, and "subjectification" in relation to social institutions. The former is expansive and ecological, an account of self in critical relations to others and the environment based on ethike or "care of the self" extended to others (see also Keddie, 2016). These are two different forms of fashioning the self: the accountability version observes power in a process of normalization; the ethic of care provides a potential basis for resistance to power that is inherent in Foucault's later works The Hermeneutics of the Subject (2005), The Government of the Self and Others (2010) and The Courage of the Truth (2011) that together sketch a subject of responsibility for others.

Today many countries hold teachers responsible for providing appropriate moral training and education. Increasingly, accountability extends beyond achievement results to questions of moral and political influence. As a social activity, depending on many factors including the degree of relationship between teacher and student, the teachers charisma, intelligence, knowledge, powers of persuasion, and other influences on a young person (e.g. family, politics, religion), the teacher can have a profound and influential effect on the ethical and political self-constitution of youth for good or for bad. The concern from ancient times to the present about the influence of teachers, education and indoctrination on youth poses a vital moral question: to what extent is it reasonable to hold a teacher responsible for a student's subsequent actions?

\section{References}

Besley, T \& Peters, M.A. (2007) Subjectivity and Truth: Foucault, Education and the Culture of Self. New York: Peter Lang. 
Eshleman, A. (2009) Moral responsibility. In Edward N. Zalta (Ed.), The Stanford encyclopedia of philosophy. Stanford, CA: Stanford University Press. Retrieved from http://plato.stanford.edu/archives/sum2014/entries/moral-responsibility/.

Foucault, M. (2005) The Hermeneutics of the Subject: Lectures at the College de France 1981-1982. New York: Palgrave Macmillan US.

Foucault, M. (2008) The Birth of Biopolitics: Lectures at the Collège de France, 1978-1979, trans. Graham Burchell, (Ed,) Arnold I. Davidson. New York: Palgrave Macmillan.

Foucault, M. (2010) The Government of the Self and Others: Lectures at the Collège de France 1982-1983. Burchell, G., Davidson, A.I. (Eds.) London: Palgrave Macmillan UK. Foucault, M (2011) The Courage of the Truth. Palgrave Macmillan UK.

Gershoff, E. (2017) School corporal punishment in global perspective: prevalence, outcomes, and efforts at Intervention. Psychology, Health \& Medicine. 22 (sup1): 224-239.

Global Initiative to End all Corporal Punishment for Children, https://endcorporalpunishment.org/. accessed November 2018.

Guskey, T.R. (1984) The influence of change in instructional effectiveness upon the affective characteristics of teachers. American Educational Research Journal, 21(2), 245-259. doi:10.2307/1162442.

Guskey, T.R. (1988) Teacher efficacy, self-concept, and attitudes toward the implementation of instructional innovation. Teaching and Teacher Education, 4(1), 63-69.

Halvorsen, A.-L., Lee, V.E., \& Andrade, F.H. (2009) A mixed-method study of teachers attitudes about teaching in urban and low-income schools. Urban Education, 44(2), 181-224.

Keddie, A. (2016) Children of the market: performativity, neoliberal responsibilisation and the construction of student identities, Oxford Review of Education, 42:1, 108-122, D OI: 10.1080/03054985.2016.1142865.

Lauermann, F. (2013) Teacher responsibility: Its meaning, measure, and educational implications (Unpublished PhD dissertation). University of Michigan, Ann Arbor, MI.

Lee, V.E., \& Smith, J.B. (1996) Collective responsibility for learning and its effects on gains in achievement for early secondary school students. American Journal of Education, 104(2), 103-147.

Lee, V.E., \& Smith, J.B. (1997) High school size: Which works best and for whom? Educational Evaluation and Policy Analysis, 19(3), 205-227.

Lemke, T. (2001) 'The birth of bio-politics': Michel Foucault's lecture at the Collège de France on neo-liberal governmentality, Economy and Society, 30 (2): 190-207.

Lenk, H. (Ed.). (1992) Zwischen sissenschaft und ethik. Frankfurt am Main: Suhrkamp Verlag.

Linn, R.L. (2006) Educational accountability systems. Los Angeles, CA: CRESST.

Linn, R.L. (2010) A new era of test-based educational accountability. Measurement: Interdisciplinary Research and Perspectives, 8(2-3), 145-149. 
O'Malley, P. (2009) Responsibilization, Sage Dictionary of Policing Eds Alison Wakefield \& Jenny Fleming, London, Sage, pp. 276-277.

Peters, M.A. (2005) The New Prudentialism in Education: Actuarial rationality and the entrepreneurial self, Educational Theory, 55 (2): 123-137.

Peters, M.A. (2001) Education, Enterprise Culture and the Entrepreneurial Self: A Foucauldian Perspective, Journal of Educational Enquiry, Vol. 2, No. 2: 58-71.

Peters, M.A., Besley, A.C., Olssen, M, Maurer, S, \& Weber, S. (2009) Governmentality Studies in Education. Rotterdam: Sense Publishers.

Schraw, G. (2010). No school left behind. Educational Psychologist, 45(2), 71-75.

Williams, G. (n.d.). Responsibility. The Internet Encyclopedia of Philosophy. Retrieved from http://www.iep.utm.edu/responsi/.

Winter, P.A., Brenner, D.B., \& Petrosko, J.M. (2006). Teacher job satisfaction in a reform state: The influence of teacher characteristics, job dimensions, and psychological states. Journal of School Leadership, 16(4), 416-437. 